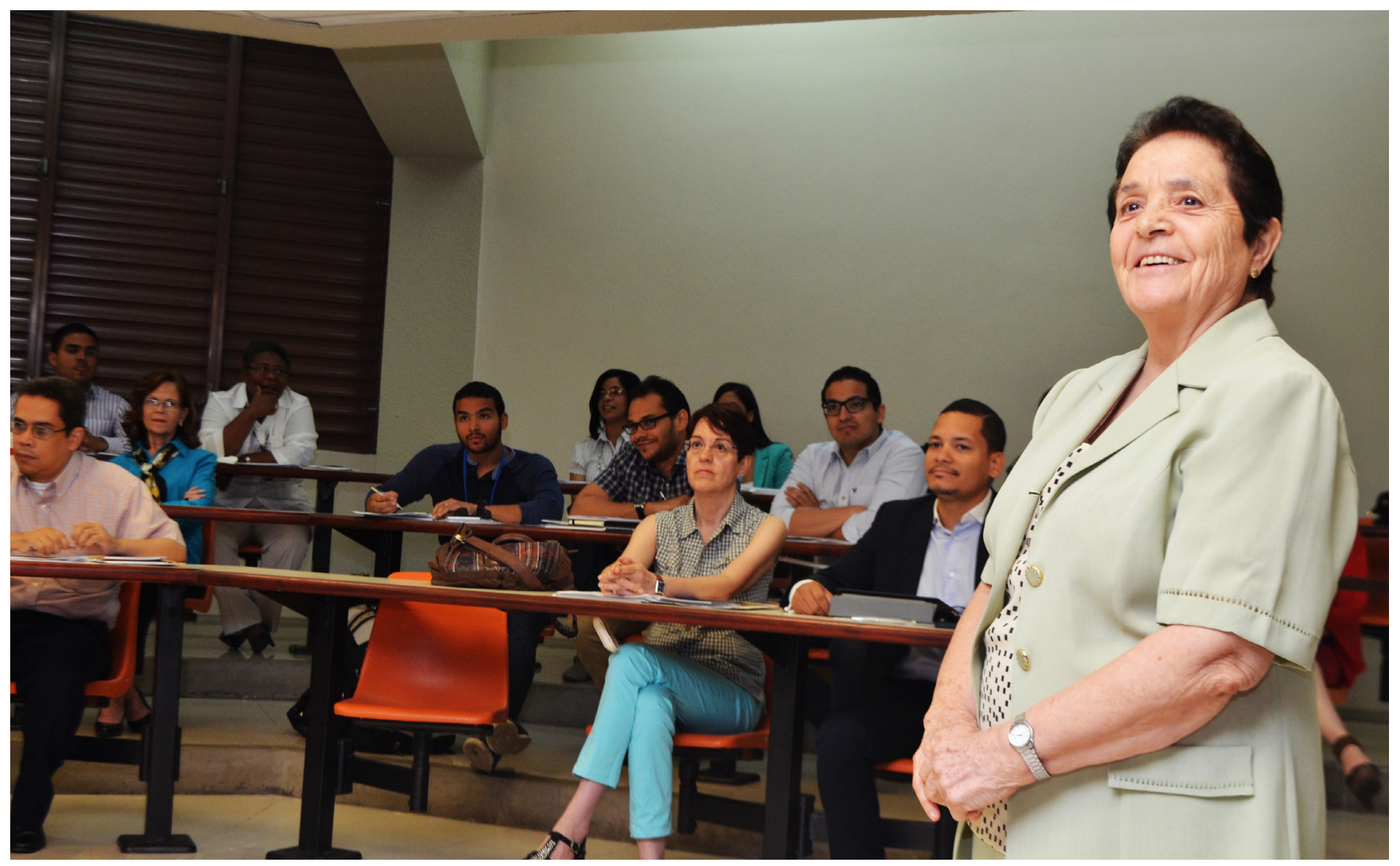

\title{
Entrevista a Oliva Hernando
}

\section{¿Quién es Oliva Hernando y cómo se implica en la educación?}

Nací en la meseta castellana, Valladolid, España, fui enviada a este país por mi congregación, donde estoy a las puertas de cumplir 53 años residiendo aquí. Desde mi llegada a Santiago, me sentí como en mi casa, acogida con mucho cariño y generosidad. Soy religiosa de la Congregación de la Hijas de Jesús que en el núcleo de su carisma y misión está inscrita la dedicación a la educación integral cristiana. Me considero ser maestra por vocación y lo vivo y recreo cada día con mucho agradecimiento, gozo, alegría y gran pasión.

Mi experiencia docente se remonta al año 1964, cuando llego al país procedente de España, y en ese mismo año recibo mi primer nombramiento como maestra en el sector público y desde distintos puestos y funciones lo desarrollé durante 42 años, con mucho agradecimiento, orgullo y entusiasmo, hasta ser jubilada en el año 2006. Junto al desempeño de mi profesión como educadora en el sector público, he venido desempeñando otras actividades educativas diversas y en distintos lugares, "buscando siempre el bien de las personas, antes que el bienestar personal" como se inscribe en mi Congregación de las Hijas de Jesús.

\section{¿Cómo se involucra en la enseñanza de la PUCMM y cuál ha sido su trayectoria?}

Invitada por la vicerrectora académica de entonces, Sarah González, a quien de verdad admiro y aprecio como persona y profesional, entro a laborar en la PUCMM en el año 1998 como profesora por asignatura en el Departamento de Educación.

Pasado muy poco tiempo, me invita también, a impartir un curso al profesorado sobre currículo, concretamente cómo debía elaborarse el programa de una asignatura.

Este curso cobra para mi gran sentido y significado en dos dimensiones, porque comienzo trabajando lo curricular a lo que en la actualidad me estoy dedicando y porque constituye el primer paso que abre el camino a la larga cadena de cursos diversos facilitados al profesorado, durante varios años, desde el Centro de Desarrollo Profesoral, donde he podido ejercer y desarrollar mi vocación de educadora, colaborando con gran gusto, pasión y entrega en la formación del profesorado de la PUCMM. 
En estos inicios colaboré también como profesora en los postgrados y maestrías de planificación y gestión de centros educativos que se impartían a los directivos del sistema educativo, a los que más tarde, se unen también los del sector privado. En este campo me introdujo otra maestra que también admiro, quiero y agradezco, Dulce Rodríguez, encargada de Postgrado en esos momentos.

La persona que con gran amor y maestría me acogió en el Centro de Desarrollo Profesoral fue Ana Margarita Haché, directora por mucho tiempo del mismo, a la que aprecio, admiro, quiero de verdad y estaré por siempre muy agradecida. Al lado de ella y con ella he vivido experiencias hondas, inolvidables, llenas de gran sentido, crecimiento y desarrollo humano, profesional y espiritual que han marcado y enriquecido hondamente mi persona.

Recuerdo también como algo muy especial, el primer curso que impartí como facilitadora, ya en el Centro de Desarrollo Profesoral, sobre el aprendizaje significativo, algo novedoso en aquellos momentos. Solo se inscribieron cinco profesores y de ellos llegaron a completarlo tres. El primer día, nos acompañaron también el profesor Ricardo Míniño y Ana Margarita Haché. El profesorado en esos momentos no sentía ni se planteaba la necesidad de seguir formándose y expresaba algo semejante a ¿para qué asistir a un curso si ya somos licenciados?, se creían saberlo todo. Pero convencidas de la necesidad de la formación e innovación continua del profesorado, seguimos ofreciendo oportunidades de formación para así responder desde la docencia de calidad y con más precisión a la educación integral del estudiantado y a la excelencia académica, pretensiones prioritarias de nuestra Universidad.

La situación del profesorado respecto a la necesidad de seguir formándose y aprendiendo ha ido cambiando, actualmente busca y asiste, cada vez en número mayor de participantes, a las oportunidades formativas que la Universidad planifica e implementa a través del Centro de Desarrollo Profesoral. Pronto surgió la necesidad de diseñar y ofrecer un Diplomado en Pedagogía Universitaria en el que se inscribieron 30 docentes de diversos departamentos, que ya en curso, por la exigencia y calidad del programa, y a petición de los mismos participantes, se convirtió en Especialidad en Pedagogía Universitaria. En este programa tuve el honor de ser coordinadora y docente de las dos primeras cohortes.

Más tarde, se rediseñó el Diplomado en Pedagogía Universitaria, el que existe en la actualidad, que se conformó con la recopilación y organización de todos los cursos que se venían ofreciendo por separado.
Este es el Diplomado en Pedagogía, que, habiendo tenido diversos rediseños, se ha venido implementando durante largos años y que ha cursado casi la totalidad del profesorado de la PUCMM.

\section{¿Cuál es el objetivo del Diplomado en Pedagogía Universitaria (DPU) y por qué constituye un desafío para las nuevas generaciones de profesores?}

El Diplomado en Pedagogía Universitaria es considerado como la fase inicial de un continuo formativo para el profesorado de la PUCMM, siendo este el primer peldaño de un plan de formación integrado e institucionalmente reconocido. El propósito de este programa es contribuir a profesionalizar la docencia en Educación Superior, redefiniendo el perfil del docente, con miras a la formación de profesionales reflexivos, críticos y creativos conforme a las competencias del perfil del profesorado de la PUCMM descrito en nuestro Modelo Educativo.

Durante años la PUCMM a través del Centro de Desarrollo Profesoral me ha venido brindado la oportunidad, primero de coordinar y ser facilitadora del Diplomado en Pedagogía Universitaria, ahora la de seguir siendo facilitadora.

Son muchos los grupos de Diplomado en Pedagogía Universitaria con los que he tenido la gracia de compartir tanta riqueza en los dos campus de la Universidad y son muchos los docentes que han cursado el Diplomado conmigo como facilitadora de los procesos formativos y de aprendizaje.

He tenido la dicha de conocer a muchos docentes a quienes he querido y quiero de verdad. Con ellos he compartido y vivido experiencias significativas bien hondas y gratificantes que reconozco y agradezco y que a todos nos han enriquecido y motivado. Por ellos, con gozo y alegría sigo entregando la vida en bien de su crecimiento, desarrollo integral y preparación profesional, convencida de que todo esto va más allá de ellos mismos, ya que transciende a los estudiantes y a la sociedad.

Son muchos los beneficios de este diplomado, a continuación, destacamos algunos:

Los participantes profundizan en el conocimiento de la Universidad, crecen en la identidad con la misma y se familiarizan con el Modelo Educativo haciéndose más conscientes de las responsabilidades y de los compromisos que implica ser docentes de la PUCMM.

El Diplomado en Pedagogía Universitaria provoca un desarrollo integral como personas, los participantes suelen tener expresiones como estas: "El diplomado me 
ha humanizado". "El Diplomado me ha transformado, ya no soy el mismo, en mi hay un antes y un después".

En otro sentido, se logra en grado considerable, el desarrollo y dominio del conjunto de competencias que componen la gestión pedagógica, como planificar eficientemente los procesos de enseñanza-aprendizaje y de evaluación para promover en los estudiantes la adquisición de saberes y el desarrollo de habilidades; actitudes y valores a través de distintas estrategias, como son la lectura y la escritura y la reflexión sobre su práctica, que los preparan a "aprender a aprender", a la innovación educativa y al desarrollo profesional continuo.

También se desarrollan otras competencias genéricas presentes en nuestro Modelo Educativo como el pensamiento crítico, manejo de TIC, el trabajo en equipo y la comunicación interpersonal, entre otras. Se destaca de manera especial, el valor que adquiere el trabajo en equipo y el desarrollo de relaciones dialogantes claras y respetuosas, entre los participantes y con la facilitadora, en un clima de aula gratificante, de confianza y libertad que propicia la construcción del conocimiento y refuerza la ayuda y colaboración entre todos.

En esta última versión del Diplomado en Pedagogía Universitaria estamos trabajando con un énfasis especial con el profesorado de nuevo ingreso en la Universidad, no solo con clases presenciales y estudios independientes sobre los temas pedagógicos de mayor relevancia, sino además, con un programa de acompañamiento que sigue el método de la mentoría (Velaz de Medrano Ureta, 2009) y que se entiende como "la relación establecida entre una persona con mayor experiencia en un ámbito (mentor) y otra con menor o ninguna experiencia (mentorizado), con el objetivo de facilitar y desarrollar sus competencias y la socialización, incrementando así sus posibilidades de éxito en la actividad a desempeñar".

Los participantes van pasando de entender y de actuar desde una docencia más intuitiva a una docencia más profesional. El tomar conciencia de que el estudiante es el centro y protagonista de su formación y aprendizaje y ellos los acompañantes motivadores y mediadores en sus procesos adquiere un gran sentido dando lugar a un cambio de paradigma.

\section{Además del DPU, ¿En qué otra área colabora para el beneficio del Modelo Educativo de la PUCMM?}

En los últimos años vengo colaborando, también con gusto y pasión, en el diseño curricular de la Universidad desde el Centro de Desarrollo Curricular al que pertenezco. Me dedico de manera especial, a acompañar y orientar a las comisiones de profesores de distintos departamentos, en la elaboración de los programas de las asignaturas por competencias que conforman los Planes de Estudio de las distintas carreras diseñados y rediseñados por competencias en esta Universidad.

El cumplimiento responsable de las funciones en los puestos que he desempeñado lo he desarrollado en sintonía y coherencia con los principios, valores, misión y visión y orientaciones pedagógicas pautadas en el Modelo Educativo de la PUCMM. Me he mantenido en actitud abierta y responsable en la búsqueda constante y apasionada por el saber, por la actualización e innovación constante del mismo y por compartirlo con los demás orientado al bien y beneficio de las personas y de la sociedad.

\section{¿Cuál ha sido la mayor satisfacción de su vida académica?}

Contemplar cómo Dios actúa, recrea y transforma de manera integral a las personas con quienes comparto en los procesos formativos y de enseñanza, no es más que una gracia muy especial que disfruto, gozo y agradezco cada día. En este sentido, lo que más me satisface es la entrega de mi vida en la formación y el desarrollo de las personas, colaborando como instrumento en las manos de Dios, desde la educación. Para mejor comprensión, dejo que la palabra de Dios ilumine lo que acabo de expresar, que con claridad me lleva a verme y vivir como instrumento de Dios del que se vale para hacer su obra recreativa y transformadora en las personas: "Yo planté, Apolo regó, pero era Dios quien hacia crecer. Así que, ni el que planta cuenta ni el que riega, sino Dios que hace crecer... Nosotros somos colaboradores de Dios; vosotros sois alabanza de Dios y construcción de Dios". 1Cor. 3, 6-7; 9.

Me causa gran satisfacción también el que todo este camino lo he recorrido con el corazón lleno de alegría y agradecimiento a Dios por haberme dado la vocación de educadora y las ricas y adecuadas cualidades personales con que me ha adornado como maestra. Junto con esto, agradezco también desde lo más profundo a los participantes en los procesos, que son muchos, al equipo del Centro de Desarrollo Profesoral, a las personas e instituciones que me han acogido y brindado la gran oportunidad de poder ejercer mi clara vocación de educadora, y de manera muy especial, a esta mi querida Pontificia Universidad Católica Madre y Maestra.

Me llena de gran satisfacción también, el haber recorrido con mucha responsabilidad, rigurosidad científica, seriedad profesional, preparación, empeño y con mucha pasión este bendito itinerario desde mi ser inquieto, siempre en búsqueda de conocimientos, estudio constante y reflexión continua. Todo, hecho desde la fidelidad a Dios en el seguimiento a Jesús y buscando siempre el bien y crecimiento de las personas; principios y valores que están en sintonía con la naturaleza y misión de la PUCMM y con los valores del Humanismo Cristiano en los que se fundamenta. 